\title{
Salivary and serum $\alpha$-amylase activity and their correlations with oxidative stress index among different iraqi smokers groups
}

\begin{abstract}
$\alpha$-amylase, which is considered as a psychological stress marker, is present in human body in two isoenzymes, salivary and pancreatic $\alpha$-amylase. Psychological stress has been reported to influence the development of tobacco dependence, in which there is a common believe that smoking reduces the effect of stress .The high smoking prevalence among people facing social and economic deprivation suggests that smoking may be used as a self-medicating method of coping with stress. The main objective of the present study is to look for the effect of different types of smoking on the activity of serum and salivary $\alpha$-amylase $\&$ to follow the change (if any) of their forms among the different smokers groups using gel electrophoresis. According to the obtained results it can be concluded that salivary amylase is more affected by smoking than pancreatic amylase \& the pancreatic amylase in $(C S \& N)$ group was the most affected group among others.
\end{abstract}

Keywords: narghile, cigarette, serum and salivary $\alpha$-amylase, oxidative stress index, psychological stress
Volume 4 Issue I - 2017

\author{
Hathama Razooki Hasan, Rasha Jamal Jabir \\ Department of Chemistry, College of Science, Iraq
}

\author{
Correspondence: Hathama Razooki Hasan, Department of \\ Chemistry, College of Science, Baghdad, Iraq, \\ Email hathamahasan@scbaghdad.edu.iq, \\ hathama2012@gmail.com
} Received:September 18, 2017 | Published: November 24,
2017
Abbreviations: PAGE, polyacrylamide gel electrophoresis; SAMS, sympatho-adrenomedullary system; SFR, salivary flow rate; DNA, deoxyribonucleic acid; RNA, ribonucleic acid; OSI, oxidative stress index; ROS, reactive oxygen species.

\section{Introduction}

Tobacco habit encountered around the world is fundamentally in the form of tobacco smoking, tobacco snuff and tobacco chewing use, while in India, tobacco is used in the form of bidis (34\%), cigarettes (30\%), chewing tobacco $(19 \%)$, hookah (narghile) $(9 \%)$, cigars and cheroots $(5 \%)$, and snuff $(2 \%),{ }^{1}$ In Iraq the smokers mostly use either cigarette, or narghile and sometime their combination. The works of many chemists and biologists over the past 50 years have shown the harmful effects of many tobacco components. ${ }^{2}$ Today tobacco is the single most common preventable cause of death in the world. In the $20^{\text {th }}$ century, more than 100 million people died worldwide due to use of tobacco and tobacco related products. ${ }^{3}$ Even though the pancreas has been reported as one of the first organs pathologically affected by the tobacco smoking, the mechanism of its effect of action is not eventually recognized. ${ }^{4}$ The exocrine function of pancreas involves the production of many enzymes used in the digestive process including serum alpha amylase. ${ }^{5}$ Tobacco smoke has been pointed out to contain multiple agents with cytotoxic or carcinogenic effects on the exocrine pancreas as well as the existence of a close correlation between cigarette smoking and pancreatic cancer. ${ }^{6}$ Moreover cigarette smoking among other reported bad effect on the body has been implicated as a risk factor for the development of pancreatitis, the exact mechanism of which remains controversial. ${ }^{7}$ One of the suggested mechanism is the injury to the pancreatic acinar cells causes a complex cascade of events that includes increased production of reactive oxygen species (ROS) resulting in the oxidation of lipids and proteins and disruption of the pancreatic membrane. ${ }^{7}$ On the other hand it was reported that during smoking, free radicals are formed that can activate inflammatory cells which generate high levels of reactive oxygen metabolites. ${ }^{8}$ Tobacco smoke contains a stimulant, nicotine, "which is a highly addictive drug such as heroin, or cocaine. Nicotine creates a pleasant feeling which makes the smoker wants to smoke more. ${ }^{9}$ A common belief is that smoking reduces aversive effects of stress, particularly negative effect, but there is relatively little behavioural evidence of this..$^{10}$ A recent systematic review of attitudes to narghile smoking affirmed this and added that the main motives for its use were socializing, relaxation, pleasure and entertainment. ${ }^{11}$ Others believe that stress could increase smoking by dampening responses to nicotine, that is, smokers may smoke more after stress to compensate for attenuated effects. ${ }^{10}$

However, recent research suggests, that psychosocial stress can sometimes leads to augmented resilience to oxidative damage and thus long-term exposure to psychological stressors may enhance the risk of many diseases. ${ }^{12}$ Salivary biomarkers have gained popularity in stress research as it has proven superior to testing biomarkers in blood. Scientists have found more promising ways of analyzing salivary biomarkers and apply them to stress research. ${ }^{13}$ This is based on the fact that saliva sample have many advantages such as wide range of constituents, non-invasive and easy and do not need trained staff. At also does not cause additional stress in sample collection unlike blood or urine collection. ${ }^{14}$ Alpha-Amylase (EC 3.2.1.1) in animals is a major digestive enzyme with optimum $\mathrm{pH}$ of (6.7-7.0). It is secreted by the salivary gland and pancreas, and so present in saliva and serum. It hydrolyzes the $\alpha-1,4$ linkages of starch to glucose and maltose. ${ }^{15}$ Serum $\alpha$-amylase is commonly measured in the diagnosis of pancreatic disorders. ${ }^{16}$ Salivary amylase has been investigated in numerous behavioral studies as a potential non-invasive and sensitive biomarker of acute stress-induced activity of the sympathetic nervous system. ${ }^{17}$ Studies by Bosch et al. ${ }^{18}$ and Skosnik et al. ${ }^{19}$ reported an increase in the salivary amylase level by psychological stress. So it has been used as a biomarker for such type of stress. ${ }^{17}$ The high smoking prevalence among people facing social and economic deprivation suggests that smoking may be used as a self-medicating method of coping with stress. ${ }^{20}$ In a previous work carried on in our laboratory oxidative stress status were measured in Iraqi smokers using different types 
of smoking. ${ }^{21}$ This article focuses on the variation in the activity of serum and salivary alpha-amylase in Iraqi individuals using different types of smoking [cigarette (CS), cigarette \& narghile (CS\&N) and narghile $(\mathrm{N})$ in comparison with non-smokers control group $(\mathrm{C})$ ] and to follow the changes in this enzyme isoenzyme among the different studied groups using gel electrophoresis technique, thereafter, we examined the relationship of these enzyme activities with OSI among the smokers groups.

\section{Materials \& methods}

\section{Materials}

All chemicals used in this study were of analytical grade.

Participant's criteria: The study was performed on (95) participants. They were Iraqi male with age ranged between 20-28 years). The study participants were divided into four groups, three of them were smoker groups, while the fourth group were healthy, age matched nonsmoker male to be used as control for the comparison. The participants of the current study are the same who had been included in our previous study therefore the detailed information of the participants and samples collection are as described in our previous work. ${ }^{21}$ The local Ethics committee of the College of Science approved the study protocol.

\section{Methods}

Determination the activity of alpha amylase:22 Amylase activity was determined using Caraway Somogyi starch-iodine amylase method. Where $\alpha$-amylase hydrolyzes the starch to maltose and other fragments. The amount of starch which remains at the end of the incubation period is detected by the addition of an iodine solution, which produces a blue-black color.

\section{Calculation}

Amylase activity:

$$
\text { Amylase } U / I=\frac{A B-A T}{A B} \times 1480 *
$$

The factor of 1480 which is used to calculate amylase activity in $\mathrm{U} / \mathrm{L}$ is derived from:

$\frac{100}{0.02} \times \frac{0.4}{5} \times \frac{15}{7.5} \times 1.85$

Where:

Amount of serum or plasma used in the test is $0.02 \mathrm{ml}$.

Amount of starch used $0.4 \mathrm{mg}$.

Incubation time 7.5 minutes.

The value 1.85 is the factor used to convert Caraway Somogyi units $/ 100 \mathrm{ml}$ to $\mathrm{U} / \mathrm{L}$, based on the formation of $0.185 \mathrm{~mol}$ reducing group per minute so that 1 Somogyi unit $/ 100 \mathrm{ml}$ equals $1.85 \mathrm{U} / \mathrm{L}$ under these conditions.

Somogyi amylase units: A Somogyi unit of amylase is defined as the amount of amylase per $100 \mathrm{ml}$ of serum or plasma that hydrolyzes $5 \mathrm{mg}$ of starch in 15 minutes at $37^{\circ} \mathrm{C}$ to the point at which it no longer gives a blue color with iodine.

(Note:) The samples have been diluted with physiological saline (serum 1:3 \& saliva 1:250) then the result was multiplied by dilution factor.

Specific activity: The specific activity of the enzyme was expressed in $\mathrm{U}$ per $\mathrm{mg}$ of protein.

Specific activity $(U / \mathrm{mg})=$ Enzyme activity $(U / L) /$ Total proteinconcentration $(\mathrm{mg} / \mathrm{L})$

Oxidative stress index: $:^{23}$ The ratio of TOS to TAC represents the oxidative stress index (OSI), an indicator of the degree of oxidative stress. This value was calculated according to the formula:

OSI $($ arbitrary unit $)=\operatorname{TOS}\left(\mu m o l H_{2} \mathrm{O}_{2} E q / L\right) / T A S(\mu m o l$ Trolox Eq / L $)$

The used TOS \& TAS were measured in our previous work. ${ }^{21}$

\section{Polyacrylamide Gel Electrophoresis (PAGE) ${ }^{24,25}$}

Conventional polyacrylamide gel electrophoresis: In this study, conventional polyacrylamide gel electrophoresis $(7.5 \%)$ was carried out according to LKB 2117 Note, to look for the changes (if any) in the amylase iso-forms among the different smokers groups.

Samples for electrophoresis: Pooled samples of sera \& saliva samples of the three smokers groups, as well as the control groups were analyzed by electrophoresis. All participants of the study were overnight fasting \& asked to rinse their mouth with normal saline, before giving the saliva samples. [Each pooled samples contributed equally to the same protein concentration] ( $25 \mu \mathrm{l}$ of serum) \& ( $10 \mu \mathrm{l}$ of saliva) and were loaded on the gel for $\alpha$-amylase detection].

Staining for amylase activity: The gel was stained for amylase activity by using starch, as a substrate and as described by Merritt. ${ }^{26}$

Statistical analysis: All statistical analyses were performed using SPSS program, Version16.0 under Windows (Statistical Package for Social Science, Inc., Chicago, IL, USA). Descriptive analysis was used to show the mean and standard deviation of variables. The significance of difference between mean values was estimated by Student independent T-test and $\mathrm{P}$-value $<0.05$ was considered significant and $\mathrm{P}$-value $<0.01$ was considered a high significant.

\section{Results}

The amylase activity was measured in sera samples of cigarette, cigarette\& narghile, narghile and non-smoker groups, as described in material \& methods section. The amylase activity (U/L), and specific activity $(\mathrm{U} / \mathrm{mg})$ of sera samples are presented in Table 1 . The results in Table 1 reveal that although an increase in both serum amylase activity and specific activity is observed in all smokers groups but this increase is not significant $(\mathrm{P}>0.05)$ in comparison to that of the control nonsmokers group. The amylase activity was measured as well in saliva samples of the same participants as described in Materials and Methods section \& the results are illustrated in Table 2.

These results show presence of a significant increase $(\mathrm{P}<0.05)$ in amylase activity of the $(\mathrm{N})$ group in comparison to that of control group. Meanwhile in spite of both (CS) as well as (CS\&N) groups showing an increase in amylase activity in comparison to that of control group, this increase is not significant $(\mathrm{P}>0.05)$. The specific activity of $(\mathrm{CS} \& N)$ group shows a significant increase $(\mathrm{P}<0.05)$ with a high increase $(\mathrm{P}<0.01)$ in $(\mathrm{CS})$ group \& no significant difference $(\mathrm{P}>0.05)$ in $(\mathrm{N})$ group in comparison to that of the control group. Using the oxidative stress index as a combined measurement through a ratio between pro and antioxidant we calculated it in serum \& saliva samples using the previously measured TOS \& TAS in our laboratory 
for the same participants. ${ }^{21}$ The obtained results are presented in Table 3. As it is clear from the above results there is no significant increase in $(\mathrm{OSI})$ in serum of all smokers $(\mathrm{CS}),(\mathrm{CS} \& \mathrm{~N}) \&(\mathrm{~N})$ groups in comparison to the control group, while this parameter in saliva shows a significant decrease $(\mathrm{P}<0.05)$ in $(\mathrm{CS} \& \mathrm{~N})$ group with no significant Table I Serum alpha amylase activity of the three smokers groups [cigarette (CS), cigarette \& narghile (CS\&N), narghile (N)] in comparison to that of the control group $(C)$ decrease $(\mathrm{P}>0.05)$ in $(\mathrm{CS})$ as well as in $(\mathrm{N})$ group upon comparison to that of the control group. A conventional PAGE (7.5\%) was used to follow the changes in the amylase profile iso-forms in the sera and saliva samples of all the studied groups.

\begin{tabular}{|c|c|c|c|c|c|}
\hline Parameters & Groups & Mean $\pm S D$ & Groups & Mean $\pm S D$ & P-Value \\
\hline \multirow[t]{3}{*}{$\alpha$-amylase serum $\mathrm{U} / \mathrm{L}$} & (C) $n=22$ & $215.09 \pm 85.3$ & $(C S) n=30$ & $232.4 \pm 73.2$ & 0.42 \\
\hline & & & $(C S \& N) n=25$ & $243.4 \pm 77.2$ & 0.28 \\
\hline & & & $(N) n=18$ & $226.6 \pm 74.6$ & 0.7 \\
\hline \multirow[t]{3}{*}{ Specific activity* 10-3U/mg } & (C) $n=22$ & $3.04 \pm 0.11$ & $(C S) n=30$ & $3.6 \pm 0.12$ & 0.11 \\
\hline & & & $(C S \& N) n=25$ & $3.7 \pm 0.12$ & 0.08 \\
\hline & & & $(N) n=18$ & $3.3 \pm 0.13$ & 0.48 \\
\hline
\end{tabular}

Table 2 Salivary alpha amylase activity of the three smokers groups [cigarette (CS), cigarette \& narghile (CS\&N), narghile (N)] in comparison to that of the control group $(\mathrm{C})$

\begin{tabular}{|c|c|c|c|c|c|}
\hline Parameters & Groups & Mean \pm SD & Groups & Mean $\pm S D$ & P-Value \\
\hline \multirow[t]{3}{*}{$\alpha$-amylase saliva $U / L * 104$} & (C) $n=22$ & $3.306 \pm 0.107$ & $(C S) n=30$ & $3.44 I \pm 0.364$ & 0.129 \\
\hline & & & $(C S \& N) n=25$ & $3.372 \pm 0.278$ & 0.361 \\
\hline & & & $(N) n=18$ & $3.47 I \pm 0.37 \mid$ & $0.031 *$ \\
\hline \multirow[t]{3}{*}{ Specific activity U/mg } & (C) $n=22$ & $19.51 \mid \pm 5.350$ & $(C S) n=30$ & $26.747 \pm 7.466$ & $0.003 * *$ \\
\hline & & & $(C S \& N) n=25$ & $27.118 \pm 3.370$ & $0.041 *$ \\
\hline & & & $(\mathrm{N}) \mathrm{n}=18$ & $19.463 \pm 4.908$ & 0.979 \\
\hline
\end{tabular}

Table 3 Oxidative Stress Index (OSI) level in the three smokers groups [cigarette (CS), cigarette \&narghile (CS\&N), narghile (N)] in comparison to that of the control group (C)

\begin{tabular}{llllll}
\hline Parameters & Groups & Mean \pm SD & Groups & Mean \pm SD & P-Value \\
\hline OSI Serum & (C) $n=22$ & $0.043 \pm 0.035$ & $(\mathrm{CS}) \mathrm{n}=30$ & $0.058 \pm 0.045$ & 0.185 \\
& & & $(\mathrm{CS} \& N) \mathrm{N}=25$ & $0.054 \pm 0.043$ & 0.358 \\
& & & $(\mathrm{~N}) \mathrm{n}=18$ & $0.045 \pm 0.031$ & 0.897 \\
OSI saliva & $(\mathrm{C}) \mathrm{n}=22$ & $0.055 \pm 0.029$ & $(\mathrm{CS}) \mathrm{n}=30$ & $0.043 \pm 0.032$ & 0.178 \\
& & & $(\mathrm{CS} \& N) \mathrm{N}=25$ & $0.038 \pm 0.025$ & $0.034^{*}$ \\
& & & $(\mathrm{~N}) \mathrm{n}=18$ & $0.040 \pm 0.030$ & 0.167
\end{tabular}

*Differences are statistically significant $(\mathrm{P}<0.05)$.

Figure $1 \& 2$ show the electrophoresis pattern obtained for sera and saliva of (CS, CS \& N, N and C) group, in reference to Figure 1 it is clear that the serum amylase activity is located at two different parts of the gel, one with slow mobility (S-type) and the other with fast mobility (P-type). The stained activity bands are obvious among all the studied groups with no difference in their location. Upon comparison of the salivary amylase separation pattern (Figure 2), it is clear that one activity band appear for each group of which the broadest and the most intense are slightly different in (CS) \& (CS\&N) groups. The Pearson correlation between (serum and serum) and (saliva and saliva) of the studied groups were done to investigate if any correlation exists between the amylase activity as a marker of psychological stress and OSI \& the results are illustrated in Table 4.

It is noticed from (Table 4 A1, B1, C1, D1, A2, B2, C2 \& D2) no obvious correlation exists between the studied enzymes and the oxidative stress index, except in saliva of $(C S \& N)$ group where a positive correlation is clear. Another aim of the present study was to look up the possibility of using saliva to follow up the changes in the studied parameters as an alternative fluid to serum. Therefore, the correlations between the changes in the two fluids were calculated \& the results are presented in Table 5 . 


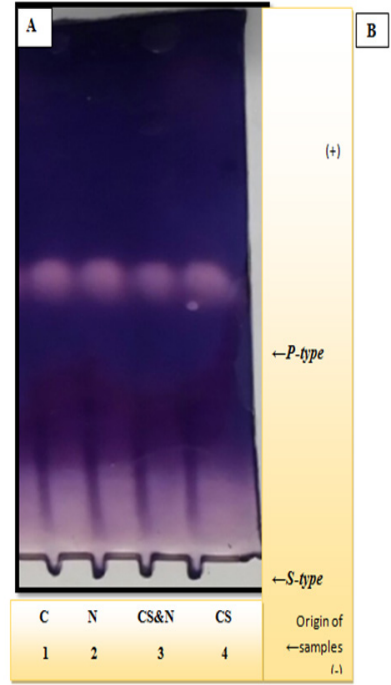

Figure I Conventional continuous polyacrylamide gel electrophoresis (PAGE) 7.5\%, using Tris-glycin buffer, $\mathrm{pH} 8.9$ as electrode buffer.

Electrophoresis was carried out using a constant current of $40 \mathrm{~mA} \&$ voltage of $15 \mathrm{v} / \mathrm{cm}$. The gel was stained for amylase activity. The samples were applied as follows:

I. Crude pooled serum control (C) group.

2. Crude pooled serum narghile $(\mathrm{N})$ group.

3. Crude pooled serum cigarette and narghile (CS\&N) group.

4. Crude pooled serum cigarette (CS) group

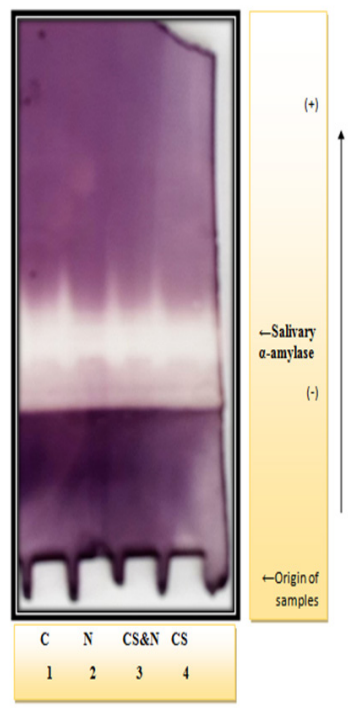

Figure 2 Conventional discontinuous polyacrylamide gel electrophoresis (PAGE) 7.5\%, using Tris-glycin buffer, $\mathrm{pH} 8.9$ as electrode buffer.

Electrophoresis was carried out using a constant current of $40 \mathrm{~mA} \&$ voltage of $15 \mathrm{v} / \mathrm{cm}$. The gel was stained for amylase activity. The samples were applied as follows:

I. Crude pooled saliva control (C) group.

2. Crude pooled saliva narghile $(\mathrm{N})$ group.

3. Crude pooled saliva cigarette and narghile (CS\&N) group.

4. Crude pooled saliva cigarette (CS) group.
Table 4 The Pearson correlation between (serum and serum) and (saliva and saliva)

Table A I The studied parameters in serum control group

\begin{tabular}{lll}
$\begin{array}{l}\text { Serum control } \\
\text { group }\end{array}$ & $\boldsymbol{\alpha}$-Amylase & Specific Activity $\boldsymbol{\alpha}$-Amylase \\
\hline OSI & -0.247 & -0.330 \\
$\alpha$ - amylase & & $0.627^{* *}$ \\
\hline
\end{tabular}

Table B I The studied parameters in serum cigarette group

\begin{tabular}{lll}
\hline $\begin{array}{l}\text { Serum cigarette \& } \\
\text { Narghile group }\end{array}$ & $\boldsymbol{\alpha}$-Amylase & Specific $\boldsymbol{\alpha}$ - Amylase \\
\hline OSI & $-0.704^{*}$ & -0.575 \\
$\alpha$-amylase & & $0.924^{* *}$ \\
\hline
\end{tabular}

Table CI The studied parameters in serum cigarette \& narghile group

\begin{tabular}{lll}
$\begin{array}{l}\text { Serum cigarette } \\
\text { group }\end{array}$ & $\boldsymbol{\alpha}$-Amylase & Specific $\boldsymbol{\alpha}$-Amylase \\
\hline OSI & $0.502^{*}$ & -0.212 \\
$\boldsymbol{\alpha}$-amylase & & 0.329 \\
\hline
\end{tabular}

Table DI The studied parameters in serum narghile group

\begin{tabular}{lll}
\hline $\begin{array}{l}\text { Serum narghile } \\
\text { group }\end{array}$ & $\boldsymbol{\alpha}$-Amylase & Specific $\boldsymbol{\alpha}$-Amylase \\
\hline OSI & -0.187 & -0.099 \\
$\alpha$-amylase & & $0.733^{* *}$ \\
\hline
\end{tabular}

Table A2 The studied parameters in saliva control group

\begin{tabular}{lll}
\hline Saliva control group & $\alpha$-Amylase & Specific $\boldsymbol{\alpha}$-Amylase \\
\hline OSI & 0.040 & -0.048 \\
$\alpha$-amylase & & 0.139 \\
\hline
\end{tabular}

Table B2 The studied parameters in saliva cigarette group

\begin{tabular}{lll}
\hline $\begin{array}{l}\text { Saliva cigarette } \\
\text { group }\end{array}$ & $\boldsymbol{\alpha}$-Amylase & Specific $\boldsymbol{\alpha}$-Amylase \\
\hline OSI & $0.621^{*}$ & 0.216 \\
$\alpha$-amylase & & -0.269 \\
\hline
\end{tabular}

Table C2 The studied parameters in saliva cigarette \& narghile group

\begin{tabular}{lll}
\hline $\begin{array}{l}\text { Saliva cigarette } \& \\
\text { Narghile group }\end{array}$ & $\boldsymbol{\alpha}$-Amylase & Specific $\boldsymbol{\alpha}$-Amylase \\
\hline OSI & 0.450 & -0.092 \\
$\boldsymbol{\alpha}$-amylase & & -0.281 \\
\hline
\end{tabular}

Table D2 The studied parameters in saliva narghile group

\begin{tabular}{lll}
\hline $\begin{array}{l}\text { Saliva narghile } \\
\text { group }\end{array}$ & $\boldsymbol{\alpha}$ - Amylase & \multicolumn{1}{c}{ Specific $\boldsymbol{\alpha}$ - Amylase } \\
\hline OSI & -0.045 & 0.151 \\
$\boldsymbol{\alpha}$-amylase & 0.023 \\
**Correlation is significant at the 0.01 level (2-tailed). \\
*Correlation is significant at the 0.05 level (2-tailed).
\end{tabular}


Table 5 The correlations between the changes in the two fluids

Table 5A Non smokers control group (C)

\begin{tabular}{lcll}
\hline Serum/Saliva & OSI & Amylase & $\begin{array}{l}\text { Specific activity } \\
\text { amylase }\end{array}$ \\
\hline OSI & 0.207 & & \\
Amylase Activity & & -0.423 & \\
Specific Activity Amylase & & -0.157 \\
\hline
\end{tabular}

Table 5B Cigarette smoker group (CS)

\begin{tabular}{lcll}
\hline Serum/Saliva & OSI & Amylase & $\begin{array}{l}\text { Specific activity } \\
\text { amylase }\end{array}$ \\
\hline OSI & -0.213 & & \\
Amylase Activity & & -0.237 & \\
Specific Activity Amylase & & 0.016 \\
\hline
\end{tabular}

Table 5C Cigarette and narghile group (CS\&N)

\begin{tabular}{lccl}
\hline Serum/Saliva & OSI & AMY & Specific activity amylase \\
\hline OSI & 0.382 & & \\
Amylase Activity & & -0.003 & \\
Specific Activity Amylase & & -0.438 \\
\hline
\end{tabular}

Table 5D Narghile group (N)

\begin{tabular}{lccl}
\hline Serum/Saliva & OSI & AMY & Specific activity amylase \\
\hline OSI & -0.223 & & \\
Amylase Activity & & 0.08 & \\
Specific Activity Amylase & & -0.001 \\
\hline
\end{tabular}

From the results in (Table $5 \mathrm{~A}, \mathrm{~B}, \mathrm{C}, \mathrm{D}$ ), it is clear that there is no correlation in the studied parameters between serum and saliva.

\section{Discussion}

Many studies showed that nicotine plays a significant role in the induction of pancreatic pathophysiology. ${ }^{27-32}$ The mechanism of this effect remains elusive and has not been established yet. ${ }^{29}$ The results of the present study show an increase in serum amylase activity in all the three smokers groups in comparison to that of the control group but this increase is not significant $(\mathrm{P}>0.05)$ (Table 1). Dubick et al., ${ }^{33}$ reported the basal serum amylase activity was $100 \%$ higher in cigarette smokers group, than in the non-smokers one. ${ }^{33}$ Such increase can be explained based on other study observation in which a sustained increased intraductal pressure is induced by the complex pharmacological actions of nicotine pressure which leads to subclinical pancreatic cell injury, and eventually cause an elevation in the level of pancreatic enzyme in the blood. ${ }^{6}$ The current study result disagrees with Weiner and Nagler observation that the unsaturated aldehydes present in cigarette smoke inhibit salivary $\alpha$-amylase activity ${ }^{34,35}$ Salivary alpha amylase is a candidate substance to indicate autonomic activity since secretion from human salivary glands occurs in response to neurotransmitter stimulation and salivary glands are innervated by both sympathetic and parasympathetic nerves. ${ }^{36}$ The activation of the sympatho-adrenomedullary system (SAMS) results in the release of catecholamine, which is difficult to track in the saliva because of its low concentration, rapid degradation and hormone instability in the samples taken. ${ }^{37}$ Chatterton et al. ${ }^{19}$ reported that there was a good association between the concentration of salivary amylase and the blood levels of catecholamine. Therefore, the measurement of this salivary enzyme is considered as a useful tool for evaluating the sympatho-adrenomedullary system (SAMS). ${ }^{38}$ It is also possible to use the enzyme $\alpha$-amylase as a response of the SAM system to stress, or as biomarkers of stress, as alternative indices of adrenergic activity, due to their stability in the saliva and reliability of the obtained values. ${ }^{37}$ SAMS activation during psychological stress increases plasma nor epinephrine, with a consequent increase in the production and release of alpha-amylase. ${ }^{39}$ On the other hand the obtained results showed in Table 2 provide an experimental evidence that saliva $\alpha$-amylase increased significantly in $(\mathrm{N})$ smokers when compared with tobacco non-consumers, with a none significantly increased in (CS) \& (CS\& $\mathrm{N})$ groups. The result was in line with that done by Onyesom who studied $\alpha$-amylase activities in serum and saliva of some Nigerian cigarette smokers and with Gomina, who studied serum and salivary $\alpha$-amylase activity in habitual adult tobacco consumers. They both reported, a significantly increased in salivary $\alpha$-amylase activity in tobacco smokers consumers than in non-consumers and suggested that such increase results from the increased secretion of $\alpha$ - amylase from salivary gland due to cigarette smoking. ${ }^{15,40}$

Alpha amylase is known to not require co-enzyme but they are calcium metallo-enzyme. ${ }^{41}$ Calcium $(\mathrm{Ca})$ is the fifth most abundant mineral in the human body. This ion is reported to play an important role in this enzyme activity and stability. ${ }^{42}$ The laboratory studies have found that activation of multiple signal transduction pathways as a result of nicotine exposure results in high levels of intracellular calcium release and suggest this may be responsible for cell cytotoxicity and cell injury. ${ }^{29}$ According to Jenkins, there is an increase in the concentration of salivary calcium ions when the saliva flow rate is high. ${ }^{43}$ A study by Nakonieczna-Runicka et al., found an elevated concentration of $\mathrm{Ca}^{+2}$ in both male and female smokers. ${ }^{44}$ Early study reported that amylase activity increases with saliva flow rate, and generally this activity is considered to be a reliable marker of serous cell function. ${ }^{45}$ Therefore, the observed slight increase in amylase activity in this study may be due to the increase in salivary flow rate (SFR) among all the smokers groups under the present study.

The observed increase in amylase specific activity in the case of (CS) \& (CS\&N) groups (Table 2) seems to be the result of the increase in its gene expression. Further study is required to prove this conclusion using larger number of samples \& taking into consideration the total exposure time to the smoke ( $i$ :e the number of cigarette smoke/day, the period that a person has been smoking, their age \& gender as factors which probably affect the obtained results $\&$ influence the risk of developing disease. Psychological stress and distress have been associated with higher levels of oxidative damage. It is considered as a potent contributor to oxidative damage, possibly through the production of free radicals in autoxidation of catecholamines. ${ }^{46}$ Oxidative stress reflects a state of cellular imbalance, in which ROS production exceeds antioxidant mechanisms that neutralize ROS, resulting in oxidative damage to nearby molecules, such as DNA, RNA and lipids. ${ }^{47}$ There is speculation on the interplay between chronic tobacco cigarette consumption \& oxidative stress. Meanwhile previous study reported that one of the main pathways of the pancreatic cell damage induced by cigarette smoke is via oxidative stress. ${ }^{48}$ Therefore in this article the oxidative stress index (OSI) which is the most accurate method to express oxidative stress, was calculated in 
the different studied groups. The results of the present study reveals no significant difference in (OSI) in serum of all smokers groups and in saliva of (CS) as well as $(\mathrm{N})$ group in comparison to the control group. This parameter show a significantly decrease $(\mathrm{P}<0.05)$ in saliva of $(\mathrm{CS} \& \mathrm{~N})$ group in comparison to that of non-smokers. The result disagrees with that of Kurku et al. ${ }^{49}$ which reported an increase in serum and salivary OSI value in Turkish cigarette smokers. ${ }^{49}$ This disagreement may be explained by the reference in the race of the used population, period of smoking, age of participants, etc. The present study was carried out on Iraqi individuals, we do believe that their bodies have been adopted to cope with all kind of stress more than other worldwide population. Since they have been exposed to many types of pollution due to many wars they have to pass through and the different weapons they have been subjected to.

Finally, according to a positive correlation which has been found in $(C S \& N)$ group between salivary $\alpha$-amylase \& OSI, and to the obtained results of the studied parameters, we observed that saliva is more affected by smoking than serum. This may be because saliva is a first body fluid to confront inhaled smoke and a synergistic, deleterious, interaction take place between smoking and saliva. While in serum we noticed that $(C S \& N)$ group was the most affected group than others \& this may be explained as the combined effect of different composition of the smoked products and different temperatures involved in this type of smoking. Based on the fact that amylase activity increased in psychological stress ${ }^{36} \&$ the observed slight increase in $\alpha$-amylase activity in all smokers groups in the present study it may be proposed that instead of helping people relax, smoking actually increases anxiety and tension. The feeling of relaxation is temporary and soon gives a way to withdrawal symptoms and increased cravings. So, although smoking reduces withdrawal symptoms, which are similar to the feelings of anxiety, it does not reduce anxiety or deal with the underlying causes. ${ }^{50}$

\section{Conclusion}

The most prominent findings of the present study are: Salivary $\alpha$-amylase is more affected by smoking than pancreatic $\alpha$-amylase $\&$ the pancreatic $\alpha$-amylase in $(\mathrm{CS} \& \mathrm{~N})$ group was the most affected group among others. Moreover there is no correlation between the observed changes that take place in serum with saliva.

\section{Acknowledgements}

None.

\section{Conflict of interest}

The author declares no conflict of interest.

\section{References}

1. Doni BR, Patil S, Peerapur BV, et al. Estimation and comparison of salivary immunoglobulin A levels in tobacco chewers, tobacco smokers and normal subjects. Oral Health Dent Manag. 2013;12(2):105-111.

2. Jasim Mohammed B, AL-Thwani AN, Kannan R. Demographic and genetic study for a sample of Iraqi smokers. Cancer Biology. 2016;6(4):16-27.

3. WHO Report on the Global Tobacco Epidemic. Tobacco Free Initiative (TFI), WHO, Switzerland, Geneva; 2017.

4. Milnerowicz H, Sliwińska M, Jabłonowska M, et al. Effect of tobacco smoking on amylase activity in patients with pancreatitis. Przegl Lek. 2004;61(10):1071-1072.
5. Bishop ML, Schoeff LE, Fody EP. Clinical Chemistry Techniques, principle and Correlation. Lippincott Williams \& Wilkins, Pennsylvania, USA; 2013.784 p.

6. Azab NY, Dawood A. Effect of Smoking on Serum Amylase and Lipase Enzymes. J Am Sci. 2012;8(11):406-410.

7. Robles L, Vaziri ND, Ichii H. Role of Oxidative Stress in the Pathogenesis of Pancreatitis: Effect of Antioxidant Therapy. Pancreat Disord Ther. 2013;3(1):112.

8. Jansen E, Beekhof P, Ruskovska T. The Effect of Smoking on Biomarkers of (Anti)oxidant Status. J Mol Biomark Diagn. 2014;5(6):207.

9. Aslam M, Asif M, Altaf S. Estimation of Smoking Index for Male Smokers in Multan City. Pakistan Journal of Nutrition. 2011;10(1):80-85.

10. Childs E, de Wit H. Effects of acute psychosocial stress on cigarette craving and smoking. Nicotine Tob Res. 2010;12(4):449-453.

11. Jawad M, Power G. Prevalence, correlates and patterns of waterpipe smoking among secondary school students in southeast London: a cross-sectional study. BMC Public Health. 2016;16(108):2-6.

12. Wang L, Muxin G, Nishida H, et al. Psychological stress-induced oxidative stress as a model of sub-healthy condition and the effect of TCM. Evid Based Complement Alternat Med. 2007;4(2):195-202.

13. Yi TC, Moochhala S. Mini-Review Article - Current Opinion on Salivary Biomarkers as a Measurement for Stress and Fatigue. The Open Biomarkers Journal. 2013;6:9-14.

14. Heberd A, Razali A, Mahalingam RS, et al. Assessment of Salivary Biomarkers Associated with Occupational Stress. International Academic Research Journal of Social Science. 2015;1(2):107-111.

15. Gomina M, Badirou L, Akpona SA. Activity of Serum and Salivary a-Amylase in Habitual Adult Tobacco Consumers. Biochem Anal Biochem. 2013;2:140

16. Noto Y, Sato T, Kudo M, et al. The relationship between salivary biomarkers and state-trait anxiety inventory score under mental arithmetic stress: A pilot study. Anesth Analg. 2005;101(6):1873-1876.

17. Nater UM, Rohleder N. Salivary alpha-amylase as a non-invasive biomarker for the sympathetic nervous system: current state of research. Psychoneuroendocrinology. 2009;34(4):486-496.

18. Bosch JA, Brand HS, Ligtenberg TJ, et al. Psychological stress as a determinant of protein levels and salivary-induced aggregation of Streptococcus gordonii in human whole saliva. Psychosom Med. 1996;58(4):374-382.

19. Skosnik PD, Chatterton RT Jr, Swisher T, et al. Modulation of attentional inhibition by norepinephrine and cortisol after psychological stress. Int J Psychophysiol. 2000;36(1):59-68.

20. Williams JM, Ziedonis D. Addressing tobacco among individuals with a mental illness or an addiction. Addict Behav. 2004;29(6):1067-1083.

21. Hasan HR, Jabir RJ. Oxidative stress status, Nitric oxide and Peroxynitrite levels in sera and saliva of Iraqi smokers. RJPBCS. 2017;8(3):1414 1424 .

22. Caraway WT. A stable starch substrate for the determination of amylase in serum and other body fluids. Am J Clin Pathol. 1959;32(1):97-99.

23. Güney T, Alișik M, Akinci S, et al. Evaluation of oxidant and antioxidant status in patients with vitamin B12 deficiency. Turk J Med Sci. 2015;45(6):1280-1284.

24. Protein Electrophoresis Technical Manual. Handbook. USA: Amersham Biosciences; 1999. 82 p.

25. Laemmli UK. Cleavage of structural proteins during the assembly of the head of bacteriophage T4. Nature. 1970;227(5259):680-685. 
26. Merritt AD, Rivas ML, Bixler D, et al. Salivary and pancreatic amylase: electrophoretic characterization and genetic studies. Am J Hum Genet. 1973;25(5):510-522.

27. Lau PP, Dubick MA, Yu GS, et al. Dynamic changes of pancreatic structure and function in rats treated chronically with nicotine. Toxicol Appl Pharmacol. 1990;104(3):457-465.

28. Chowdhury P, Hosotani R, Chang L, et al. Metabolic and pathologic effects of nicotine on the gastrointestinal tract and pancreas of rats. Pancreas. 1990;5(2):222-229.

29. Chowdhury P, MacLeod S, Udupa KB, et al. Pathophysiological effects of nicotine on the pancreas: an update. Exp Biol Med (Maywood). 2002;227(7):445-454.

30. Chowdhury P, Doi R, Tangoku A, et al. Structural and functional changes of rat pancreas exposed to nicotine. Int J Pancreatol. 1995;18(3):257264.

31. Wittel UA, Hopt UT, Batra SK. Cigarette smoke-induced pancreatic damage: experimental data. Langenbecks Arch Surg. 2008;393(4):581588 .

32. Wittel UA, Pandey KK, Andrianifahanana M, et al. Chronic pancreatic inflammation induced by environmental tobacco smoke inhalation in rats. Am J Gastroenterol. 2006;101(1):148-159.

33. Dubick MA, Conteas CN, Billy HT, et al. Raised serum concentration of pancreatic enzymes in cigarette smokers. Gut. 1987;28(3):330-350.

34. Weiner D, Levy Y, Khankin EV, et al. Inhibition of salivary amylase activity by cigarette smoke aldehydes. J Physiol Pharmacol. 2008;59(6):727-737.

35. Nagler R, Lischinsky S, Diamond E, et al. Effect of cigarette smoke on salivary proteins and enzyme activities. Arch Biochem Biophys. 2000;379(2):229-236.

36. Nater UM, Rohleder N, Gaab J, et al. Human salivary alpha-amylase reactivity in a psychosocial stress paradigm. Int $J$ Psychophysiol. 2005;55(3):333-342.

37. Ivković N, Božović Đ, Račić M, et al. Biomarkers of Stress in Saliva. Scientific Journal of the Faculty of Medicine in Niš. 2015;32(2):91-99.

38. Takai N, Yamaguchi M, Aragaki T, et al. Effect of psychological stress on the salivary cortisol and amylase levels in healthy young adults. Arch Oral Biol. 2004;49(12):963-968.
39. Campos MJ, Raposo NR, Ferreira AP, et al. Salivary alpha-amylase activity: a possible indicator of pain-induced stress in orthodontic patients. Pain Med. 2011;12(8):1162-1166.

40. Onyesom I, Osioma E, Ifie EJ, et al. Activities of Alpha Amylase in Serum and Saliva of Some Nigerian Cigarette Smokers. Advances in Life Sciences. 2012;2(1):28-30.

41. Butterworth PJ, Warren FJ, Ellis PR. Human $\alpha$-amylase and starch digestion: An interesting marriage. Review. 2011;63(7):395-405.

42. Nassar M, Hiraishi N, Islam MS, et al. Age-related changes in salivary biomarkers. Journal of Dental Sciences. 2014;9(1):85-90.

43. Jenkins GN. The physiology and biochemistry of the mouth. 4th ed. Blackwell Scientific, Oxford, Philadelphia, USA, 1978. 599 p.

44. Fattahi Bafghi A, Goljanian Tabrizi A, Bakhshayi P. The Effect of Smoking on Mineral and Protein Composition of Saliva. Iran J Otorhinolaryngol. 2015;27(81):301-305

45. Khan GJ, Mehmood R, Salah-ud-Din, et al. Secretion of calcium in the saliva of long term tobacco users. J Ayub Med Coll Abbottabad. 2005;17(4):60-62.

46. Tsuber V, Kadamov Y, Tarasenko L. Activation of antioxidant defenses in whole saliva by psychosocial stress is more manifested in young women than in young men. PLoS One. 2014;9(12):e115048.

47. Aschbacher K, O’Donovan A, Wolkowitz OM, et al. Good stress, bad stress and oxidative stress: Insights from anticipatory cortisol reactivity. Psychoneuroendocrinology. 2013;38(9):1698-1708.

48. Topsakal S, Ozmen O, Aslankoc R, et al. Pancreatic damage induced by cigarette smoke: the specific pathological effects of cigarette smoke in the rat model. Toxicology Research. 2016;5(3):938-945.

49. Kurku H, Kacmaz M, Kisa U, et al. Acute and chronic impact of smoking on salivary and serum total antioxidant capacity. J Pak Med Assoc. 2015;65(2):164-169.

50. Lawrence D, Mitrou F, Zubrick SR. Smoking and mental illness: results from population surveys in Australia and the United States. BMC Public Health. 2009;9:285 p. 